\title{
Building a Library GIS Service from the Ground Up
}

\author{
RHONDA HOUSER
}

\begin{abstract}
Geographic Information Systems (GIS) services in academic libraries tend to differ, based on availability of GIS data, software, hardware, and staff expertise. GIS services at the University of Kansas are closely aligned with support for government information, data, maps, and statistics. Thus, our responses to users' needs are often naturally collaborative, optimizing the expertise of multiple staff members and various types of resources. The GIS and Data Specialist assists campus researchers with spatial data and software, as well as facilitating access to GIS data. Lab space for research and coursework involving spatial data is a core component of GIS services. In addition, various levels and types of GIS workshops are offered each semester, and custom training sessions are also available. "Word of mouth" and hands-on workshops are some of the most effective methods of outreach.
\end{abstract}

\section{INTRODUCTION}

This article describes the development, current profile, and future directions of Geographic Information Systems (GIS) services at the University of Kansas (KU) Libraries. The intended audience of the article has at least a basic understanding of GIS and related terminology. Academic libraries considering implementing new GIS services or evaluating existing services may find this article helpful. KU Libraries supports 25,000 students and 1,300 faculty with academic and research resources. Library collections consist of approximately 3.7 million volumes and 33,000 current serial titles, housed in six facilities in Lawrence and one in Kansas City. 
KU Libraries, Information Technology, and the Policy Research Institute founded a new committee several years ago called the Academic Data Research Services Alliance (ADRSA). ${ }^{1}$ Members assist the campus research community with data identification, access, and analysis. ADRSA was instrumental in establishing the Library Geographic Information Systems (GIS) and Data Lab and in creating the GIS and Data Specialist position (hereafter referred to as GIS Specialist). GIS and Data Services is a transparent network of ADRSA partners and associated staff, which pulls from the expertise of staff in maps, data, GIS, government information, and statistics.

\section{GIS AND DATA LAB}

The GIS Specialist supports GIS-related coursework, research, and teaching at KU. Prior to such assistance being formally available, the T. R. Smith Map Collection (henceforth referred to as the Map Collection) provided basic assistance with GIS. The GIS and Data Lab (or Lab) provides a quiet working environment for individuals or groups and it includes space for use of GIS and statistical workstations, laptop use, and research design and discussion. ${ }^{2}$ The Lab was initially located in the rear of a meeting room on a lower floor of the library, with two statistical workstations set up for social science data users. Use was low, perhaps due to minimal resources and staff support and the limitations of appointment-only use. In 2002 the Lab was moved to a room next to the Map Collection, which also contained offices for the Map Librarian and new GIS Specialist. Users had relatively easy access to staff, and staff could easily monitor the Lab.

These staff offices were moved to a space behind the Lab in 2004, coinciding with initial integration of the campus statistics lab with the GIS and Data Lab. These moves added workspace and resources in the lab and grouped staff offices, but they also removed staff from the immediate Lab area. A new doorway was created to directly connect and improve communication between Lab users and support staff. Workstations now have log-ons for user authentication that are consistent with other public machines in the libraries and standardized images, such that all computers are loaded with the same basic set of programs. This profile is more secure, easier to maintain, and gives users uniformity. Users have dedicated network space for storage of data and related files. Due to the merger of these two labs, users now benefit from extensive spatial and statistical resources and a wider range of staff expertise available in the same location.

The GIS and Data Lab is generally open sixty hours per week for walk-in use and for scheduled consultations with on-site staff. Full-time staff that support users in various capacities include a GIS Specialist, Map Librarian, Data and Government Information Librarian, and Statistical Consultant. Seven powerful workstations are loaded with major GIS and statistical applications, such as ArcGIS and ArcView, SAS, SPSS, and other programs used in conjunction with GIS software, such as Excel and PhotoShop. ${ }^{3}$ Lab 
users also have access to small scanners and printers, as well as oversize scanning and printing services, formally offered for the last several years. Additional resources include GIS-related reference books and software manuals, datasets, tutorials, and current publications.

Lab workstations are also loaded with the datasets and digital manuals that accompany ArcGIS software, or "Environmental Systems Research Institute's (ESRI) Data and Maps" and "Digital Books." These datasets and digital manuals are commonly requested and provide comprehensive information on using the software and a wide array of vector and raster data for the world (Andronache et al., 2005). However, users are often unaware that these resources are available or otherwise do not install them on their own workstations. The GIS Specialist worked with other Information Services staff to make these resources available online to KU affiliates.

In addition, Lab machines include a customized ArcGIS application with current, detailed data for Lawrence obtained from the city GIS program. Aerial photos, streets, contour lines, and city parcels are some of the more commonly used datasets. This tool is particularly helpful to novice and nonGIS users, such as Urban Planning and Architecture students working on site or building design projects. Students often generate a "map" of their project area and use other programs to manipulate the resulting image. Members of the general public also use this application for local mapping information, such as a "picture" or "map" of their neighborhood.

The Lab is located in one of the two larger campus libraries that holds most of the science-oriented materials. The central location of this facility, and its proximity to one of the main campus computer labs, is convenient to most users. Furthermore, this library is near buildings that house the Architecture, Urban Planning, Geography, and Geology Departments, some of our most active patrons. A potential drawback is that we are on the ground floor of a building for which the third floor is the main entrance, and this lower visibility limits accidental discovery by new users. However, being "off the beaten path" does result in relatively quieter and cleaner work areas, and those who need to find us can do so.

A nearby campus lab has approximately twenty GIS workstations available for walk-in use. This lab serves a different purpose than the GIS and Data Lab, as it does not have GIS support staff; it is primarily used for technical workshops and so is often unavailable on weekdays. However, its evening and weekend hours complement those of the GIS and Data Lab. These labs are the only two on campus that support GIS and that are open to anyone regardless of departmental or other affiliation.

The GIS and Data Lab is next door to the Map Collection, and cooperation among map, GIS, data, and government information resources extends beyond sharing physical space. GIS often acts as a bridge between geographical and tabular information since it is comprised of both. Such service groupings have been successfully implemented at various universi- 
ties (Czarnocki and Khouri, 2004). Combined data, GIS, and maps services seemed to work well at Queen's University in Kingston, Ontario, Canada, which provides resources related to both "merging and emerging technologies" (Moon, 1993, p. 33). Soete (1997) also noted the benefits of GIS services that are closely tied to related services.

\section{GIS Assistance}

The GIS Specialist provides assistance via in-person consultations, email, and telephone through the GIS and Data Lab with frequent referrals from the Map Collection. Some common requests for assistance include the following issues and associated questions.

- Finding Specific Datasets:

I'm looking for administrative boundaries for the Soviet Union.

Is there GIS data for New Orleans (post-hurricane), such as transportation networks, census data, and debris site locations?

- Generating a Map or Image from Spatial Data:

I want to create a map (aerial photo) of downtown Kansas City, near the river market.

I need a map (aerial photo) of downtown Lawrence, showing streets and contour lines.

- Converting Data Among Various Formats, Such as Open Source Proprietary, Vector, Raster, and Compressed:

How do I convert elevation data, downloaded in DEM (Digital Elevation Model) format, into something (grid) I can use in ArcMap?

How do I convert this file for hiking trails in Yellowstone (trails.e00) into something ArcGIS will read (ArcInfo coverage)?

- Subsetting Data or Clipping Data Layers:

From country boundaries for the world data, I need Africa as a separate (vector) layer.

I only need tract boundaries and income data for Douglas County, Kansas, not the entire state.

- Creating Data, Such as Point, Line, or Polygon Features and Editing Associated (Attribute) Information:

I need to identify and digitize forested areas on top of this aerial photograph, with a topo map (DRG) as another base map.

I want to calculate the percent of population change in Montana counties for the last 100 years.

- Mapping Tabular Data Using Geographic Coordinates for Point Locations, or Collected with a Global Positioning System (GPS):

How can I map my data on protest events in North Korea? I have XY coordinates in Excel for each location where a protest occurred.

I need to get my field data out of this GPS unit and map it (that is, sunflower populations, ice core samples, wind farms) 
- Mapping Tabular Data by Linking (Joining) to a GIS Layer with the Same Geographic Variables:

I want to map child welfare data by zip code from this Excel file. How can I display the data based on a particular variable?

I have readership data for the Saturday Evening Post back to the 1920s by U.S. county and state. How can I put these data on a map?

- Integrating an Image, Such as a Scanned Map, into a GIS Using Geographic Coordinates (Georeferencing):

I need city footprints in digital format for Costa Rica.

I want to compare modern maps to historical maps created by an explorer and plot the plant populations he documented.

- Spatial Data Analysis:

What types of land cover are associated with these bird nesting areas?

How many elementary schools are located within Richmond city limits?

The source of information that fills a user need may be either paper or digital, regardless of the final format needed. For instance, information originating in digital format can be manipulated using GIS or other software, remain in digital format, or be printed via desktop printers or plotters. Likewise, information beginning in paper format can be converted to digital format via an oversize scanner and printed to a plotter for what is essentially a copy. Alternatively, a scanned item can be manipulated in GIS or other software and retained in digital format or printed to hard copy. Thus, the Map Collection may bring new users to GIS and vice versa (Cobb, 1999).

For example, a graduate student in ecology working with distribution and protection of rare bird species walks into the Map Collection looking for digital data, constituting base map features for part of Ecuador. No sufficiently detailed GIS data are freely available, but a map in the Joint Operations Graphics series is found at an appropriate scale for the desired area. As the student wants digital data to incorporate into a GIS, we scan the map and the student later georeferences the image, feeding latitude and longitude values from the map into ArcGIS.

The number of data consultations nearly doubled from 2003 (eightytwo) to 2004, and this year's monthly average was 16 percent higher than it was in 2004. The majority of users assisted in 2005 were KU-affiliated and most commonly were from the Departments of Urban Planning, Architecture, Ecology and Evolutionary Biology, and Journalism. In 2005 meetings were held most often with graduate students, followed by faculty and then students who were either undergraduates or graduates. The profile for walk-in, unassisted GIS users of the Lab is similar to the consultation user base.

GIS consultations are typically longer and more complex and technical than traditional reference questions, as is consistent with GIS services at 
other institutions (Abbott and Argentati, 1995; Deckelbaum, 1999; Suh \& Lee, 1999). To balance the increasing demand for GIS services and the extensive time required, the GIS Specialist at KU continually works to provide self-help tools, such as online datasets, software manuals, and tutorials. This does not undermine the ongoing need for in-person assistance but rather supports and may make such meetings more productive (Argentati, 1997).

Consultations are carried out such that users are guided in using spatial data and software but the work is not done for them; these meetings are learning opportunities for all parties involved (Soete, 1997). At one end of user experience and informational needs are those wanting simple facts or statistics that may be generated by stand-alone or Web-based mapping applications. These patrons may never use GIS software, which involves a fairly steep learning curve (Suh \& Lee, 1999; Deckelbaum, 1999; Soete, 1997). At the opposite end are those who want to use raw spatial data on a GIS workstation. These user profiles are similar to what Kowal (2002) defined as low- and high-level users and are reflected in the complexity of data and software appropriate for such users (Abbott \& Argentati, 1995).

For others who enjoy digging for data, some requests inevitably remain unanswered by freely available data. Some recent examples from GIS and Data Services include

- data for building footprints and heights in London

- city limits for cities in Central America

- air photos for a wine-growing region in Tuscany

- zoning data for New Orleans

- street and contour data for Kristiansend, Norway.

\section{Data Management}

In developing KU Libraries GIS services, it was important to survey library-owned spatial data, including federal depository items, commercial data, and internally generated data. Library holdings, mainly from federal agencies such as the Census Bureau and Geological Survey, are underused and very difficult to find through traditional library search mechanisms (Soete, 1997). Initial inventory attempts were unsuccessful, as library cataloging tools and staff were ineffective in generating even a rough inventory. Instead, inventory is ongoing through data requests, coincidental discovery, collection development, and monitoring of new resources. Considering the strengths of KU Libraries sheet map and data holdings, and freely available data, it is challenging to find large-scale data for places outside the United States and Canada, such as topography, political boundaries, and roads. Sweetkind-Singer and Williams (2001) also found such data onerous to obtain for free. 
Library GIS staff at KU and other institutions rarely purchase datasets, as a wealth of spatial and tabular data is freely available online and through government agencies (Abbott \& Argentati, 1995; Lamont, 1997; Kowal, 2002; Soete, 1997). Many small-scale commercial datasets are already freely available online in raw or alternative formats. Moreover, the availability of library staff with GIS expertise to assist with data manipulation reduces the need for acquiring most commercial datasets.

At KU GIS datasets and related resources are not allotted a separate collection development budget, so they are purchased through subject liaisons. KU Libraries did purchase data to complete the Global GIS database set, which provides a variety of small-scale data layers for the world (Hearn et al., 2003; American Geological Institute, 2003). GIS data generated by campus researchers and through internal and joint projects may be made available through such archival and access tools as the institutional repository and the state GIS data clearinghouse. ${ }^{4}$

\section{INSTRUCTION}

\section{Teaching GIS}

The GIS Specialist teaches GIS workshops throughout the semester with assistance from colleagues. Workshops offered on an ongoing basis are designed to teach basic to advanced skills, and they cover specialized topics in ArcGIS, such as the Spatial Analyst extension. ${ }^{5}$ Lessons focus on applying geographic concepts and questions related to spatial data while developing familiarity with software and terminology. The GIS Specialist leads these hands-on workshops, which are usually two hours long. Workshops are scheduled in cycles, as participants tend to sign up for an entire cycle instead of one at a time. Attendance is generally higher during the first half of a semester and when new workshops are introduced, but it has been steady for most workshops over the course of three years. Figures 1 and 2 describe the status and affiliation of workshop attendees.

The GIS Specialist also provides custom training sessions, such as "Moving from ArcView 3.x to ArcGIS" and "Mapping Tabular Data in a GIS." In addition, instructors may request a GIS session for a particular class. Departments that have requested GIS sessions are Architecture, Ecology and Evolutionary Biology, Environmental Studies, Geography, Journalism, Political Science, Public Administration, and Urban Planning. Teaching a workshop often initiates dialogue among participants and instructors, and many attendees use this time to discuss their GIS uses and needs or to make appointments for in-depth assistance. The GIS Specialist and related staff also provide informal training sessions, presentations, and tours to educate library staff about GIS services and help them make referrals. 


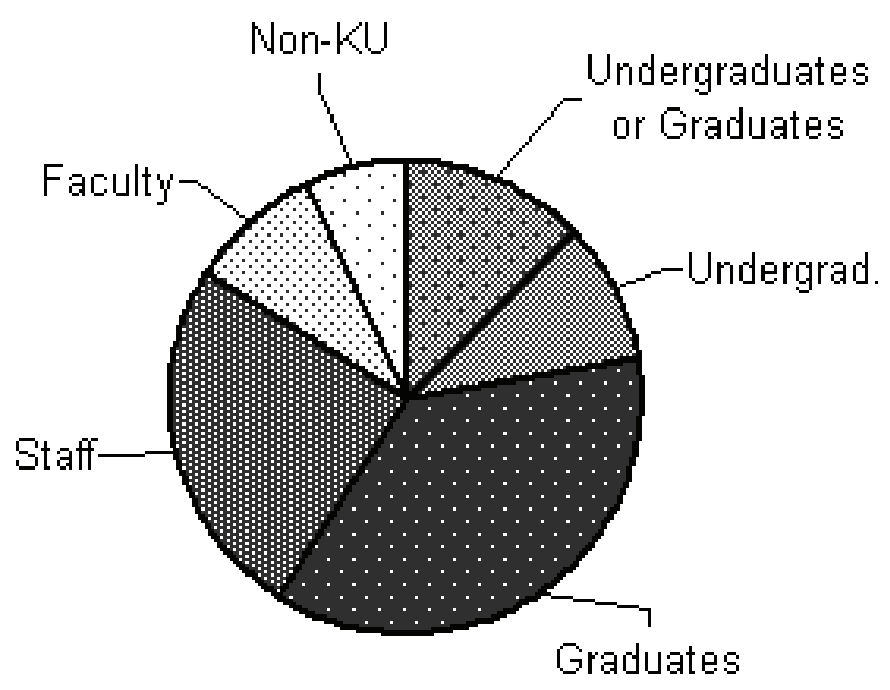

Figure 1. KU Libraries GIS Workshop Attendees, 2002-2005

\section{GIS Training}

The GIS Specialist facilitates access to educational resources such as software tools and applications, how-to guides for data and software, email list services, and tutorials. The Environmental Systems Research Institute (ESRI) online tutorials, free to KU affiliates through the campus site license, are frequently used by individuals seeking self-paced, focused training and by instructors to augment a semester course. The GIS Specialist also advises users on selecting and acquiring GIS software.

\section{Outreach}

Of perhaps more importance than developing the nuts and bolts of a GIS service is building relationships with library staff and with faculty, graduate students, and other GIS users. These relationships are the key to an effective and sustainable service and can help it evolve to meet changing user needs, as was also found by Atkins (1999) and Soete (1997). Referrals and projects arise from such relationships, both personal and professional, as patrons often come in to use the Lab by recommendation from instructors, other students, or friends. A dual method of outreach is the hands-on workshops, which help identify user needs as well as provide GIS training (Atkins, 1999).

In addition, the GIS Specialist and related staff participate in various campus events, such as GIS Day. GIS Day is a symposium sponsored primarily by the Geography Department and aimed at increasing knowledge of local GIS applications and of geographic information science. Library staff 


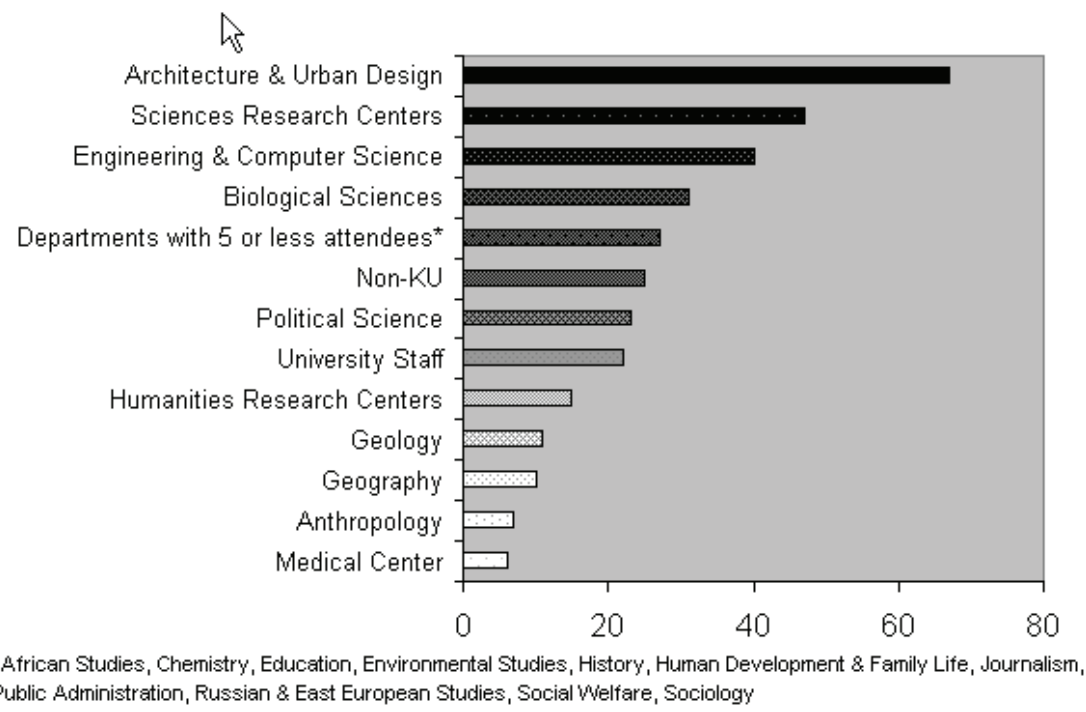

Figure 2. KU Libraries GIS Workshop Attendees, 2002-2005

have displayed GIS research posters as part of this event, judged student paper presentations, and promoted the event through GIS workshops. Events such as GIS Day are excellent opportunities to make and maintain contacts and raise awareness of library GIS services. Ongoing modes of outreach are also useful and accessible, such as email list services, direct emails, presentations, Web pages, and various publications. The GIS Specialist also works with library subject specialists in communicating with academic departments regarding GIS issues.

\section{Future Directions}

Interest in GIS is spreading steadily across many campuses (Badurek, 2000; Andronache et al., 2005; Sweetkind-Singer \& Williams, 2001). At KU interest has sparked lately in the Political Science, Geology, Environmental Studies, Public Administration, and Engineering Departments. Many of these departments have neither staff nor facilities to support GIS, and users may only consist of one or two faculty and a few graduate students. These GIS users need access to software, data, and expertise from a centralized, accessible source of research assistance, such as the library.

GIS training is also an ongoing need at $\mathrm{KU}$, particularly that which is inexpensive and convenient. The campus seems hungry for GIS training of any kind. However, hands-on training options outside the university are often cost-prohibitive. Workshops, online tutorials, and other educational 
resources help address but do not seem to fill this need. Workshop evaluations indicate that attendees would like a wider variety and higher frequency of workshops. However, developing new workshops requires a substantial amount of time; existing workshops must be revised with software upgrades and changes in data format. The library cannot and probably should not satisfy all campus GIS training needs (Argentati, 1997).

GIS and data staff hope to fully merge the GIS and Data Lab and the campus statistics lab in the coming year. Challenges include maintaining security, providing quiet work space, and giving users a sense of ownership, while remaining readily available to assist users. The GIS Specialist also seeks to increase awareness of the Lab, library spatial data holdings, and related resources such as free software training and online tutorials. Additional signage for both public space and staff offices is one way to heighten visibility of GIS services. Finally, it is demanding but essential to continually engage library staff in discussions and training related to GIS services.

\section{Conclusions}

Researchers have access to increasingly, and seemingly user-friendly, spatial applications, which offer powerful display and analysis options. Such applications can deceptively appear overly simplified because users can obtain "glossy" output from complicated datasets with the click of a button. The user may be overwhelmed or fail to appropriately interpret this surfeit of results. This can lead to the common misconception that GIS is easy to use and learn. Realistically, finding or processing spatial data usually takes twice as long as initially expected, an experience shared by Sweetkind-Singer and Williams (2001). However, visualization and analysis capabilities, and skills gained through working with the data, are worth the effort. Graduate students seem the most willing to recognize whether a new application such as GIS software is a useful research tool for their discipline, and subsequently they dive in and learn to use the program proficiently.

Lab users also often see GIS as merely a map-making tool. Compared to professional cartographic software, most GIS programs can produce basic maps with minimal effort. However, novice GIS users often generate rudimentary maps lacking a title, projection, legend, or identification of data sources. Committing more time and effort can result in fairly detailed and accurate maps, but users rarely spend this much time. Basic paper maps generated in ArcGIS should not be used as a final medium for data but rather to examine preliminary data patterns or trends, to contribute to further digital processing, or for collection of additional data (Deckelbaum, 1999). GIS is about visualization and analysis of digital spatial data, seeking answers to questions of geography, and examining relationships between geographic features within or between layers; GIS is not about creating pretty maps (Cox \& Gifford, 1997; Deckelbaum, 1999). 
Others providing campus GIS services agree that every university has different GIS needs. What is the library's niche in supporting these needs (Abbott \& Argentati, 1995; Adler, 1997; Argentati, 1997; Badurek, 2000; Lamont, 1997)? One must try to understand the GIS environment by consulting with stakeholders, such as other libraries, computer labs, research centers, and academic departments interested in GIS. For instance, GIS and maps staff at KU have developed solid working relationships with the Geography Department and the Kansas Biological and Geological Surveys, which are significant GIS users. One may also obtain useful information about campus GIS users from the GIS site license administrator. Some issues to consider are the following:

- Do GIS users have access to necessary data, software, and hardware?

- Is there a GIS lab open to anyone, regardless of department or affiliation?

- Are data storage and distribution needs met?

- Can users obtain GIS assistance from campus staff?

- Do users have access to needed training and related resources?

- How is GIS software purchased? Is a site license available, and are users taking advantage of the benefits?

- Are there commonly used datasets to which the library could facilitate access?

- Is grant funding available to support GIS services?

- Is there a means for communication among campus GIS users?

Support from library administration and related campus departments is fundamental to a successful GIS service. In addition, staff involved must possess a strong knowledge of major GIS software and computer applications in general and be committed to ongoing education on GIS data, software, and applications (Argentati, 1997; Cox \& Gifford, 1997; Kowal, 2002). Many libraries offer GIS services. As Adler also noted (1997), the question for larger academic institutions may no longer be whether to offer GIS services but what level of service to offer.

\section{Notes}

1. KU Academic Data Research Services Alliance: http://www.ku.edu/adrsa/.

2. KU Libraries GIS and Data Lab: http://www.lib.ku.edu/gis/.

3. Adobe (1990-2002), Photoshop 7.0 Software; Apache Software (1989-2003), SPSS 12.0 Software; Autodesk (2005), AutoCad; Environmental Systems Research Institute (19922002), ArcView 3.3 Software; Environmental Systems Research Institute (1999-2004), ArcGIS 9.1 Software; Microsoft (1985-1999), Excel 2000 Software; SAS Institute (2002-2003), SAS 9.1 Software.

4. KU Institutional Repository: https://kuscholarworks.ku.edu/dspace/.

5. GIS workshop descriptions and handouts available from "GIS \& statistics workshops" link: http://www.lib.ku.edu/gis/. 
REFERENCES

Abbott, L., \& Argentati, C. (1995). GIS: A new component of public service. Journal of Academic Librarianship 21(4), 251-256.

Adler, P. (1997). An introduction-Where are we heading? Geographic Information Systems (GISs) Revisited: A Symposium [Special issue]. Journal of Academic Librarianship, 23(6), $447-448$.

American Geological Institute. (2003). Global GIS database: Digital atlas of North Eurasia. Alexandria, VA: U.S. Geological Survey.

Andronache, C., Mento, B., Gaiser, T., Hon, R., Dalgin, R., \& Schreiner, A. (2005). Increasing GIS resources for teaching and research. In ESRI GIS Education Users Conference, ESRI, July 2005, San Diego, CA. Redlands, CA: ESRI.

Argentati, C. (1997). Expanding horizons for GIS services in academic libraries. Journal of Academic Librarianship, 23(6), 463-468.

Atkins, A. (1999). Library-based GIS initiative at the Illinois Institute of Technology. Illinois Libraries, 81(2), 67-74.

Badurak, C. (2000). Managing GIS in academic libraries. WAML Information Bulletin, 31(2), $110-114$.

Cobb, D. (1999). GIS: Its impact on library service. Meridian, 16, 5-8.

Cox, A., \& Gifford, F. (1997). An overview to geographic information systems. Journal of Academic Librarianship, 23, 449-461.

Czarnocki, S., \& Khouri, A. (2004). A library service model for digital data support. IASSIST Quarterly, Summer/Fall, 30-34.

Deckelbaum, D. (1999). GIS in libraries: An overview of concepts and concerns. Issues in Science EO Technology Librarianship, 21.

Hearn, P., et al. (2003). Global GIS databases: Digital atlases of Africa, Central and South American, Europe, North America, North Eurasia, South Asia, and South Pacific. Alexandria, VA: U.S. Geological Survey.

Kowal, K. (2002). Tapping the Web for GIS and mapping technologies: For all levels of libraries and users. Information Technology $\mathcal{E}$ Libraries, 21(3), 109-114.

Lamont, M. (1997). Managing geospatial data and services. Journal of Academic Librarianship, 23(6), 469-473.

Moon, J. (1993). Integration of "traditional" data centre services with GIS technology. IASSIST Quarterly, 17, 30-34.

Soete, G. (1997). Issues and innovations in geographic information systems. Washington, DC: Association of Research Libraries, Office of Management Services.

Suh, H., \& Lee, A. (1999). Embracing GIS services in libraries: The Washington State University experience. Reference Librarian, 64, 125-137.

Sweetkind-Singer, J., \& Williams, M. (2001). Supporting the information needs of Geographic Information Systems (GIS) users in an academic library. Information and the Professional Scientist and Engineer, 16, 175-191.

Rhonda Houser is the GIS and Data Specialist at the University of Kansas Libraries in Lawrence, Kansas. She holds a bachelor's and master's degree in Environmental Studies. Her thesis research focused on using Geographic Information Systems (GIS) to examine Eastern Cougar habitat in the Northern Blue Ridge of Virginia. She did GIS and mapping-related work for the Virginia Department of Conservation and Recreation before completing her master's degree in 2002. 